\title{
Climatic variability in combination with eutrophication drives adaptive responses in the gills of Lake Victoria cichlids
}

\author{
Jacco C. van Rijssel ${ }^{1,2,3,4} \cdot$ Robert E. Hecky $^{5}$ Mary A. Kishe-Machumu ${ }^{6}$. \\ Saskia E. Meijer ${ }^{1} \cdot$ Johan Pols $^{1} \cdot$ Kaj M. van Tienderen ${ }^{1} \cdot$ Jan D. Ververs $^{1}$. \\ Jan H. Wanink ${ }^{1,7} \cdot$ Frans Witte $^{1,2}$
}

Received: 8 February 2016 / Accepted: 5 September 2016 / Published online: 14 September 2016

(C) Springer-Verlag Berlin Heidelberg 2016

\begin{abstract}
Textbook examples of adaptive radiation often show rapid morphological changes in response to environmental perturbations. East Africa's Lake Victoria, famous for its stunning adaptive radiation of cichlids, has suffered from human-induced eutrophication over the past decades. This cultural eutrophication is thought to be partly responsible for the dramatically reduced cichlid biodiversity, but climatic variability in itself might also have contributed to the eutrophication which resulted in low oxygen levels and decreased water transparency. To determine how recent environmental changes have influenced the lake and its
\end{abstract}

Communicated by Joel Trexler.

Electronic supplementary material The online version of this article (doi:10.1007/s00442-016-3721-3) contains supplementary material, which is available to authorized users.

Jacco C. van Rijssel

jacco.vanrijssel@eawag.ch

1 Institute of Biology Leiden, Leiden University, 2300 RA Leiden, The Netherlands

2 Naturalis Biodiversity Center, 2300 RA Leiden, The Netherlands

3 Present Address: Fish Ecology and Evolution, EAWAG Center of Ecology, Evolution and Biogeochemistry, 6047 Kastanienbaum, Switzerland

4 Institute of Ecology and Evolution, University of Bern, 3012 Bern, Switzerland

5 Large Lakes Observatory, University of Minnesota, Duluth, MN 55812, USA

6 Tanzania Fisheries Research Institute, P.O. Box 9750, Dar es Salaam, Tanzania

7 Koeman en Bijkerk bv, Ecological Research and Consultancy, 9750 AC Haren, The Netherlands cichlids over the past 50 years, we gathered environmental and meteorological variables and compared these with gill surface area of four cichlid species. We found that during the period of severe eutrophication and temperature increase (1980s), reduced wind speeds coincided with a reduction in oxygen levels and a decrease in both water temperature and transparency. The gill surface area in three out of the four cichlid species increased during this period which is consistent with adaptive change in response to increased hypoxia. During the 2000s, wind speeds, oxygen levels, water transparency and water temperature increased again, while cichlid gill surface area decreased. Our results imply that climatic changes and especially wind speed and direction might play a crucial role in tropical lake dynamics. The changes in Lake Victoria's water quality coincide with fluctuations in cichlid gill surface area, suggesting that these fish can respond rapidly to environmental perturbations, but also that climatic variability, together with continued eutrophication, might be detrimental to the lake's cichlid biodiversity.

Keywords Climate change - Cultural eutrophication . Hypoxia $\cdot$ Morphological adaptation $\cdot$ Wind stress

\section{Introduction}

Evidence that climate change and global warming can cause dramatic perturbations in freshwater ecosystems has rapidly accumulated over the past decade (Parmesan 2006; Winder and Schindler 2004; Woodward et al. 2010). Such dynamics may induce adaptive morphological change in species via plastic and/or genetic change; however, there are few systems where morphological data are available over a time frame that permits an exploration of 
climate-induced morphological shifts. Exceptions include the Darwin's finches (Grant and Grant 2006) and East African cichlids (van Rijssel and Witte 2013; van Rijssel et al. 2015) where regular long-term monitoring of environmental and species traits provides a unique opportunity to test for the effects of environmental change on morphological traits that are predicted to facilitate persistence.

In East Africa, the warming of the Indian Ocean and the changes in the El Niño Southern Oscillation (ENSO) are believed to have resulted in an increase in air temperature and changes in rainfall (Clark et al. 2003; Funk et al. 2008; Nicholson and Kim 1997; Williams and Funk 2011). The effect of this warming on the physical properties of African Great Lakes has been well documented (Cozar et al. 2012; Hecky et al. 2010; Lorke et al. 2004; O'Reilly et al. 2003; Tierney et al. 2010; Verburg et al. 2003; Vollmer et al. 2005). To illustrate this, in Lake Tanganyika, the warming coincided with higher water temperatures (O'Reilly et al. 2003; Verburg et al. 2003) that likely resulted in decreased vertical mixing.

Periodic decreases in vertical mixing have been inferred for Lake Victoria as well during conditions of higher rainfall, reduced winds and higher relative humidity (Hecky et al. 2010; Kolding et al. 2008b). The extent of this vertical mixing is crucial for tropical lake dynamics, because it influences the exchange processes of heat and matter between different water layers and between the sediment and the water. Thus, vertical mixing is an important driver of environmental variables such as phytoplankton abundance, water transparency, and dissolved oxygen (DO) levels. A large phytoplankton biomass, together with resulting high water turbidity and low DO-levels, often are symptoms of eutrophication driven by increased nutrient loading. The eutrophication of freshwater lakes has become a worldwide issue in terms of biodiversity loss (Smith and Schindler 2009). The loss of species diversity can be inflicted in several ways, including demographic decline and introgressive hybridization. Though the latter can be beneficial for speciation during early adaptive radiation events (Seehausen 2004), it is more likely to result in the loss of biodiversity through reversed speciation (Seehausen 2006). Reversed speciation occurring through introgressive hybridization has been found in several freshwater fishes, including European whitefish, three-spined sticklebacks and East African cichlids (Seehausen et al. 1997; Taylor et al. 2006; Vonlanthen et al. 2012). This hybridization can occur when eutrophication increases the water turbidity and therefore hampers sexual selection. Cichlid and stickleback females tend to select the most conspicuously colored males for mating (Maan et al. 2004; Milinski and Bakker 1990). When eutrophication and thus water turbidity increases, mate choice will be impeded by the low water transparency and hybridization is likely to occur, resulting in speciation reversal (Seehausen et al. 1997). Eutrophication has also been found to induce speciation reversal by hybridization when whitefish habitat and diet overlap increased due to benthic oxygen depletion, which forced the benthic white fish species to spawn in the same habitat and feed on the same prey as the limnetic species (Vonlanthen et al. 2012).

The eutrophication of Lake Victoria has mainly been attributed to anthropogenic influences (Verschuren et al. 2002). However, recent studies imply that climatic changes have contributed as well (Hecky et al. 2010; Kolding et al. 2008b). The latter two studies suggest that the observed decrease in wind speeds during the 1970s and 1980s has enhanced the already inflicted eutrophication due to increased stability and persistence of seasonal stratification that resulted in deoxygenation of the hypolimnion. During this time, the enhanced primary production and increase of cyanobacteria and algae resulted in a decrease in transparency and increased hypoxia (Hecky et al. 2010; Seehausen et al. 1997). Together with the introduction of the piscivorous Nile perch Lates niloticus (Linnaeus 1758), these dramatic ecological changes are thought to be responsible for the eradication of hundreds of endemic haplochromine cichlid species (McGee et al. 2015; Seehausen et al. 1997; van Zwieten et al. 2016; Witte et al. 2007).

Although many Lake Victoria haplochromine cichlid species seem to have disappeared as a result of the environmental perturbations, some have shown signs of recovery (Kishe-Machumu et al. 2015; Witte et al. 2007) and have adjusted morphologically to the altered environment in the Mwanza Gulf of Lake Victoria (Van der Meer et al. 2012; van Rijssel et al. 2015; van Rijssel and Witte 2013; Witte et al. 2008). For example, in the Mwanza Gulf of Lake Victoria, a site where haplochromines have been monitored by the Haplochromis Ecology Survey Team (HEST) since the 1970s, Haplochromis (Yssichromis) pyrrhocephalus Witte \& Witte-Maas 1987 showed an increase in gill surface area of $64 \%$ and it was suggested that this was a response to the low oxygen conditions (Wanink et al. 2001; Witte et al. 2008). In this study, we describe long-term (50 years) changes in a series of meteorological and limnological variables in Mwanza Gulf (Fig. 1). We then quantify changes in gill surface area of four species of haplochromine cichlids from HEST collections (abbreviations of species in parentheses); H.(Y.) pyrrhocephalus (pyr), H. (Y.) laparogramma (lap) Greenwood \& Gee 1969, H. tanaos (tan) van Oijen \& Witte 1996 and Platytaeniodus degeni (deg) Boulenger 1906 to explore the relationships between variation in gill surface area and environmental change. We predicted that climatic variability would have a major effect on the lake dynamics that influence environmental variables such as water transparency and DO-levels. Other than water itself, dissolved oxygen is the first limiting physical factor for aquatic animals (Kramer 1987). Low DO-levels have a large impact on fish communities, fish behavior, physiology 


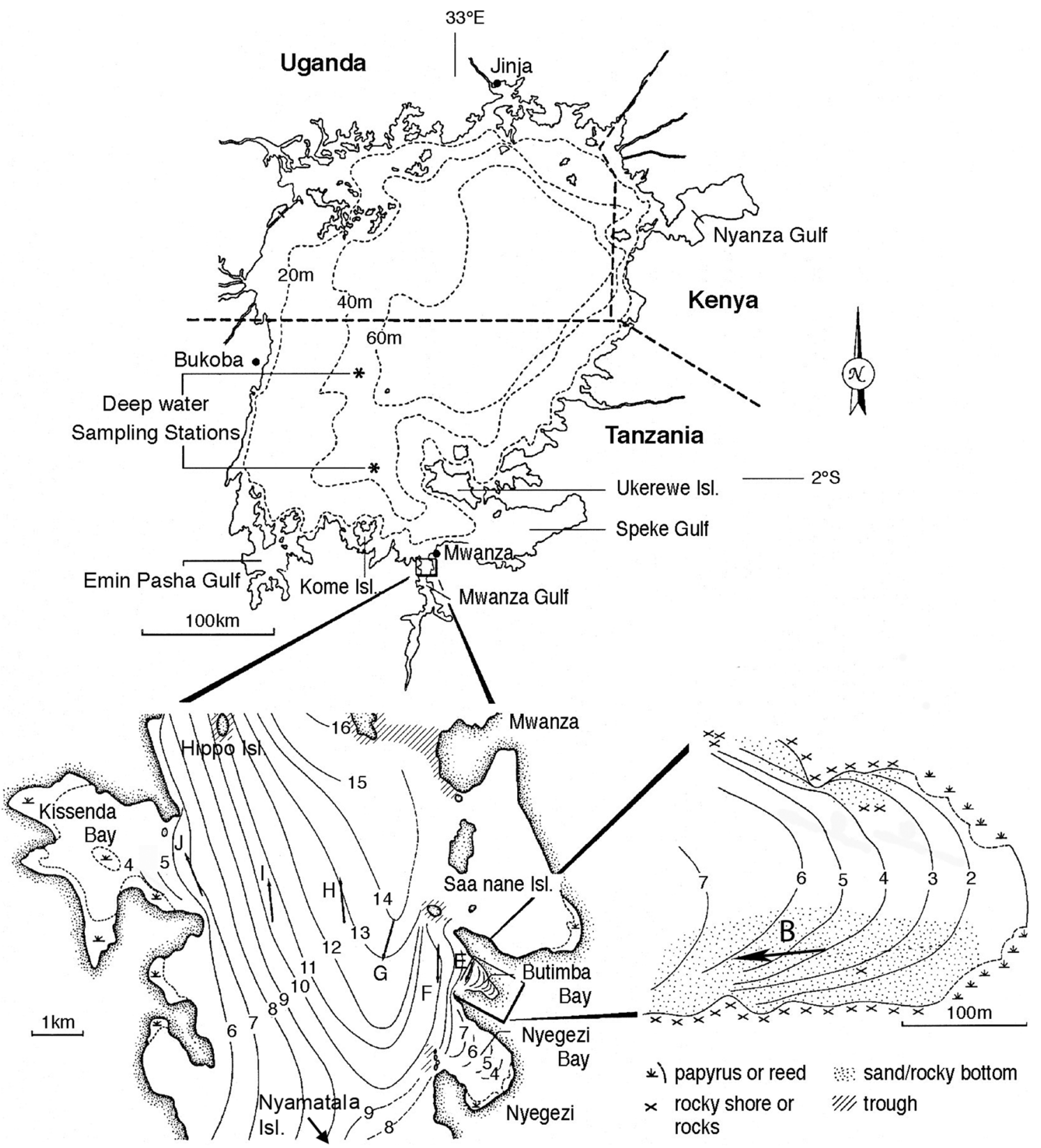

Fig. 1 Map of Lake Victoria showing the sampled research transect and stations in the northern part of the Mwanza Gulf

and morphology (Pollock et al. 2007). The gill surface area of several fish species, including cichlids (Chapman et al. 2000; Galis and Barel 1980), is known to correlate with environmental DO-levels in nature (Crampton et al. 2007; Hughes 1966; Hughes and Morgan 1973; Langerhans et al. 2007). The enlargement of the gill surface area as a response to hypoxic conditions in the laboratory has been observed for a phylogenetically wide span of teleosts including cichlids (Chapman et al. 2000; Dabruzzi and Bennett 2014; Nilsson et al. 2012; Ong et al. 2007; Rutjes 2006; Saroglia 2002; Sollid and Nilsson 2006). Therefore, a decrease of DO-levels is expected to induce an increase of the gill surface area of the four resurgent cichlid species.

\section{Materials and methods}

\section{Meteorological and physical variables}

Monthly meteorological data were obtained for the wet season (February-April) from 1960 to 2012 resulting in three monthly measurements for each year. We obtained 
data from the meteorological department measured at Mwanza Airport for minimum and maximum air temperatures (1960-2012), rainfall (1960-2012), wind speed (1972-2012) and wind direction (1977-2012). Wind speed and direction were measured at $1200 \mathrm{~h}$ during the day.

Annual data for lake water levels (1965-2012) were obtained from the Lake Victoria Basin Water Office and measured at a station located between Mwanza City and the village of Nyegezi (Fig. 1). This station is located $1130 \mathrm{~m}$ above sea level that is subtracted from the lake level measurements.

\section{Environmental variables}

The Mwanza Gulf is a relatively long, narrow gulf that extends $60 \mathrm{~km}$ southward with an average width of $5 \mathrm{~km}$ that varies in depth from 1 to $2 \mathrm{~m}$ in the southern part up to 20-25 $\mathrm{m}$ at the entrance of the gulf (Fig. 1; Goudswaard et al. 2002). Periodically, DO-levels, water transparency and the bottom and surface water temperature were measured in the years 1973-1974, 1980, 1983-1985, 1986-1987, 1988, 2002, 2006, 2008 and 2010-2011. Some years were combined into periods of multiple years to obtain sufficient data resulting in 3-12 measurements per year or per period. Most of these measurements were conducted at station G (12$14 \mathrm{~m}$ depth) of the research transect in Mwanza Gulf where most fish used in this study were caught (see below; Fig. 1). Daily DO-levels and temperature were measured $1 \mathrm{~m}$ above the bottom and at the surface between 10.00 and $14.00 \mathrm{~h}$. The surface and bottom temperature were subtracted from each other and this difference can be interpreted as an indicator of temperature-dependent density stratification. These variables were measured with a Yellow Springs Instrument (YSI) AQ model 57 (YSI Incorporated, Yellow Springs, OH, USA). while water transparency was measured with a Secchi disc (Online Resource 1). Data from 1973 to 1974 were obtained from Akiyama et al. (1977) who obtained measurements from south of Nyamatala Island at a depth of $8 \mathrm{~m}$ ( $5 \mathrm{~km}$ south of station $\mathrm{G}$ ). To correct for the depth difference with station $\mathrm{G}$, we compared the bottom water temperature, DO-levels and Secchi depth between station $\mathrm{G}$ and station $\mathrm{E}$ (also $8 \mathrm{~m}$ depth) from the same time period. The average difference was subtracted from or added to values reported by Akiyama et al. (1977). The data from 2010 to 2011 were measured by I. J. M. Cornelissen from the Disentangling the Social and Ecological Drivers of Ecosystem Change in Lake Victoria, Tanzania Research Program (SEDEC, Wageningen UR), $1 \mathrm{~km}$ south of station $\mathrm{G}$ (11 $\mathrm{m}$ depth). We selected data from the wet season (February-April) which has heavy rains, but calm weather when thermal stratification and hypoxia occur in the lower part the water column in the open water of Lake Victoria (Talling 1966) as well as in the Mwanza Gulf (Akiyama et al. 1977; Cornelissen et al. 2014; Wanink et al.
2001; Witte and van Densen 1995). This seems to be the harshest period of the year for the cichlids with lower visibility, lower DO-levels and higher water temperatures.

\section{Fish collection}

Fish were collected during the years 1981, 1984, 19861987, 1991, 1993, 1999, 2001-2002, 2006 and 2011, along the research transect in the northern part of the Mwanza Gulf, Lake Victoria, Tanzania. The species pyr and lap were mainly caught above mud bottoms at station $\mathrm{G}$, while the species $d e g$ and tan were mainly caught at sand/mud bottom bays (Butimba and Kissenda, 4-8 m depth) at opposite ends of the transect (Fig. 1; Online Resource 2).

We selected males only to avoid any effects of sexual dimorphism. In total, 214 adult fish of four species (an average of seven specimens per species per year) were selected for the gill morphology measurements from the specimens used in van Rijssel and Witte (2013).

\section{Gill morphology}

The first and second gill arches on the right side of each fish were dissected and photographed with a digital camera (Nikon Digital Sight DS-FI1, Nikon Corporation, Tokyo, Japan) mounted on a dissecting microscope. Both sides (hemibranches) of the second gill arch were photographed with a reference scale. The length $(L)$ and number $(N)$ of the filaments were measured from these photographs. Four filaments equally divided over the medial hemibranch were selected for measuring the secondary lamellae (sec. lam.). From each side, $10 \mathrm{sec}$. lam. were selected and measured from the middle of the filament using scanning electron microscopy (SEM).

A pilot study indicated no striking differences between the size and shape of the secondary lamellae on different hemibranches of the gill (Witte et al. 2008). Therefore, a reliable, indicative measure of the complete gill surface area was made by calculating the gill surface area of the second gill arch following Witte et al. (2008):

$A=N \times L \times d \times a$,

where $A$ is the gill surface area of the second gill arch $\left(\mathrm{mm}^{2}\right), N$ the total number of filaments on both hemibranches, $L$ the average filament length $(\mathrm{mm}), d$ the average sec. lam. density $\left(\mathrm{mm}^{-1}\right)$ and $a$ the average sec. lam. surface area $\left(\mathrm{mm}^{2}\right)$. The $d$ was calculated by dividing 10 by the distance between the first and the tenth sec. lam. resulting in the number of sec. lam per mm. The $a$ was calculated considering the sec. lam. as a triangle $a=l \times 1 / 2 h \times 2$, where $l$ is the sec. lam. length (mm) and $h$ is the sec. lam. height $(\mathrm{mm})$. Note that the surface area is multiplied by two because each sec. lam. has two functional sides. All measurements were conducted with ImageJ (1.47a). 


\section{Statistical analysis}

Statistical analyses on meteorological and physical variables only were performed on data categorized per year (annual dataset). Because we combined some of the environmental variables into periods, statistical analyses including environmental variables were performed on data categorized in periods (periodic dataset). Differences in environmental factors among years/periods were tested with a one-way ANOVA unless the data were not normally distributed (tested with Shapiro-Wilk test). This was the case for minimum air temperature, wind speed, lake levels and the difference between surface and bottom water temperatures which were then tested with a non-parametric Kruskal-Wallis test. A general linear model (GLM) with body volume (BV) as covariate and period as independent factor was applied to test for the effect of period on the morphological characters of the gills following van Rijssel and Witte (2013). These data were log-transformed to achieve linearity, and estimated marginal means (EMM) were anti-logged and plotted through time. To test how all the environmental variables of the periodic dataset interacted with each other over time, we applied a principal component analysis (PCA) in PAST 3.04 (Hammer et al. 2001), where the environmental variables were treated as a correlation matrix and pairwise deletion was used to correct for missing values. A Pearson correlation test was used to see if annually and periodically measured environmental variables were correlated with each other and to test if cichlid gill surface area was correlated with PC1 and PC2. Because we had very clear predictions for the effect of DOlevels on cichlid gill surface area, a one-tailed Pearson correlation test was used to see if PC 1 (which was highly correlated with DO) and DO itself were correlated with cichlid gill surface area. To test for an overall effect of the PCs on gill surface area of the four species, we performed an ANCOVA with the PCs as covariate. A Spearman correlation test was used for non-normally distributed data which was the case for minimum air temperature. The $P$ values of all tests were corrected with a sequential Bonferroni test within subgroups (indicated in table legends). Except for the PCA, all statistical tests were performed with SPSS Version 20 (IBM Corp. NY, USA).

\section{Results}

\section{Meteorological, environmental and physical variables through time}

The wind direction showed significant changes through time using the annual dataset $(P=0.003$, Fig. $2 \mathrm{a})$. In the period 1978-1981, the wind roughly came from the west $\left(253^{\circ}-266^{\circ}\right)$ and from 1982 till 1994 mainly from the southwest $\left(180^{\circ}-249^{\circ}\right.$, Fig. 2a). Three years after the change in wind direction (1985), the wind speed dropped significantly (both in the annual and the periodic dataset, $P<0.001$, Figs. 2a, b, 3a, b). From 1985 onward, the wind speed decreased and remained low until 1997, with the exception of a small peak in 1992-1993 (Fig. 3b). The wind direction changed back to mainly western winds from 1995 onward. Three years later, in 1998, the wind speed increased again and during the 2000s reached speeds above those previously recorded (Figs. 2a, b, 3a, b). Despite changes in wind speed and direction, the rainfall did not change significantly throughout time based on the annual dataset (Fig. 2c). Even though there was no overall decrease in rainfall, the lake level decreased gradually over time with a steep decline during the early 2000s ( $P<0.001 ;$ Fig. 2 c, d). Based on the annual data set, the lake level showed a significant negative correlation with wind speed $(r=-0.322, P=0.046$, Table 1$)$.

The maximum air temperature increased significantly in 1980 compared to 1960s-1970s (annual dataset, $P<0.001$, Fig. 2e). It remained high up till 2012 with the exception of a non-significant drop from 1985 till 1996 that also concurs with the period of major wind changes. The minimum air temperature remained stable during the 1960s and 1970s and then dropped gradually from 1980 onward, reaching its lowest point in $1999(P<0.001$; Fig. 2f). In 2003, the minimum air temperature increased again to the level of the 1960s and 1970s and remained at that level up till 2012.

Bottom and surface water temperature, DO-levels and Secchi depth all show a significant drop during the mid- and late 1980s compared to $1973-1974$ and $1980(P<0.001$, Fig. 3c-e) that concurs as well with the observed wind changes (Fig. 3a, b). Compared to 1973-1974, the difference between the bottom and surface temperature increased significantly in 1980 and $1983-1985(P<0.01)$, indicating increasing stratification. The increased difference was maintained, albeit at a less pronounced level, from 1987 onward, and in 2006 the difference decreased $(P<0.05)$ to a similar level as in 1973-1974. Although data from the 1990s are mostly missing, from 2002 onwards water temperature, Secchi depth and DO-levels increased again reaching the same level as they were in 1973-1974 and $1980(P<0.001)$. Secchi depth, however, showed again a significant drop in $2011(P<0.001$; Fig. 3c-e) .

\section{Gill morphology through time}

In the mid- and late 1980s when DO-levels decreased, three out of four species (pyr, lap and deg) showed a significant increase in gill surface area $(P<0.01$, Fig. 3f) with a significant effect of the covariate BV $(P<0.001$, Online Resource 3$)$. The increase was mainly due to a significant increase in filament length, sec. lam. surface ( $p y r$ and lap) 

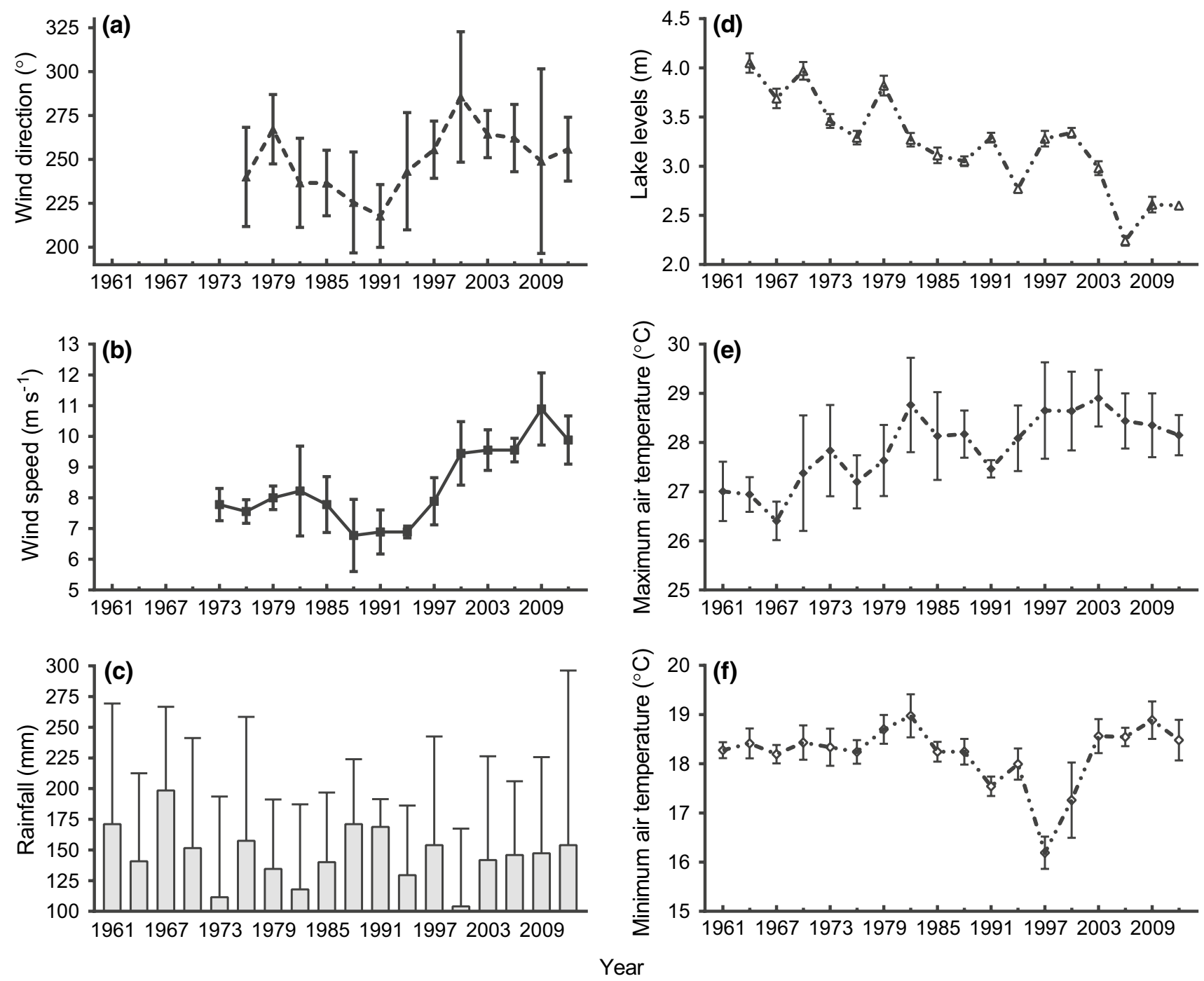

Fig. 2 Meteorological variables and lake levels plotted through time measured at Mwanza airport and between Mwanza City and the village of Nyegezi, respectively, during the wet season (FebruaryApril). a Wind direction $(N=36)$, b wind speed $(N=41)$, c rainfall $(N=53)$, d lake levels $(N=45)$, e maximum $(N=49)$ and $\mathbf{f}$ minimum air temperature $(N=53)$. Lake levels are depicted as height values with the elevation of the Mwanza Gulf $(1130 \mathrm{~m})$ extracted from

and sec. lam. density (deg, Online Resource 3 and 4). The gill surface area of the three species decreased significantly during the 2000s when the DO-levels had increased again $(P<0.05$, Fig. 3d, f). In 2011, however, there was once more a significant increase in gill surface area for $p y r$ and deg, while DO-levels were high $(P<0.05)$.

\section{Environmental and morphological variable associations}

Although the direction of the relationship between gill surface area of the four species and DO was negative, none of these trends was significant (Online Resource 5). Only the

them. For better visualization, every 3 years were averaged to 1 year with the middle year being depicted in the graph, e.g., year 1961 represents years 1960, 1961 and 1962, etc. Depicted standard deviations are based on within year measurements $(N=3)$ for all variables except for rainfall where standard deviations are based on three combined annual measurements and only upper end standard deviations are depicted

gill surface area of pyr showed a significant negative correlation with Secchi depth $(r=-0.967, P=0.002$, Online Resource 5). The first two axes of the PCA performed on the environmental variables from the periodic dataset explained $60 \%$ of the variance (Fig. 4). The first axis explained $41.3 \%$ and was strongly and positively related with wind speed, wind direction, DO-levels, Secchi depth, bottom and surface water temperature and negatively with rainfall. The occurrence of the periods in which severe environmental changes were observed ('83-85, '86/87, ' $88,{ }^{\prime} 91$ and '93) on the very negative side of PC1 indicates low values for the above-mentioned variables and high amounts of 

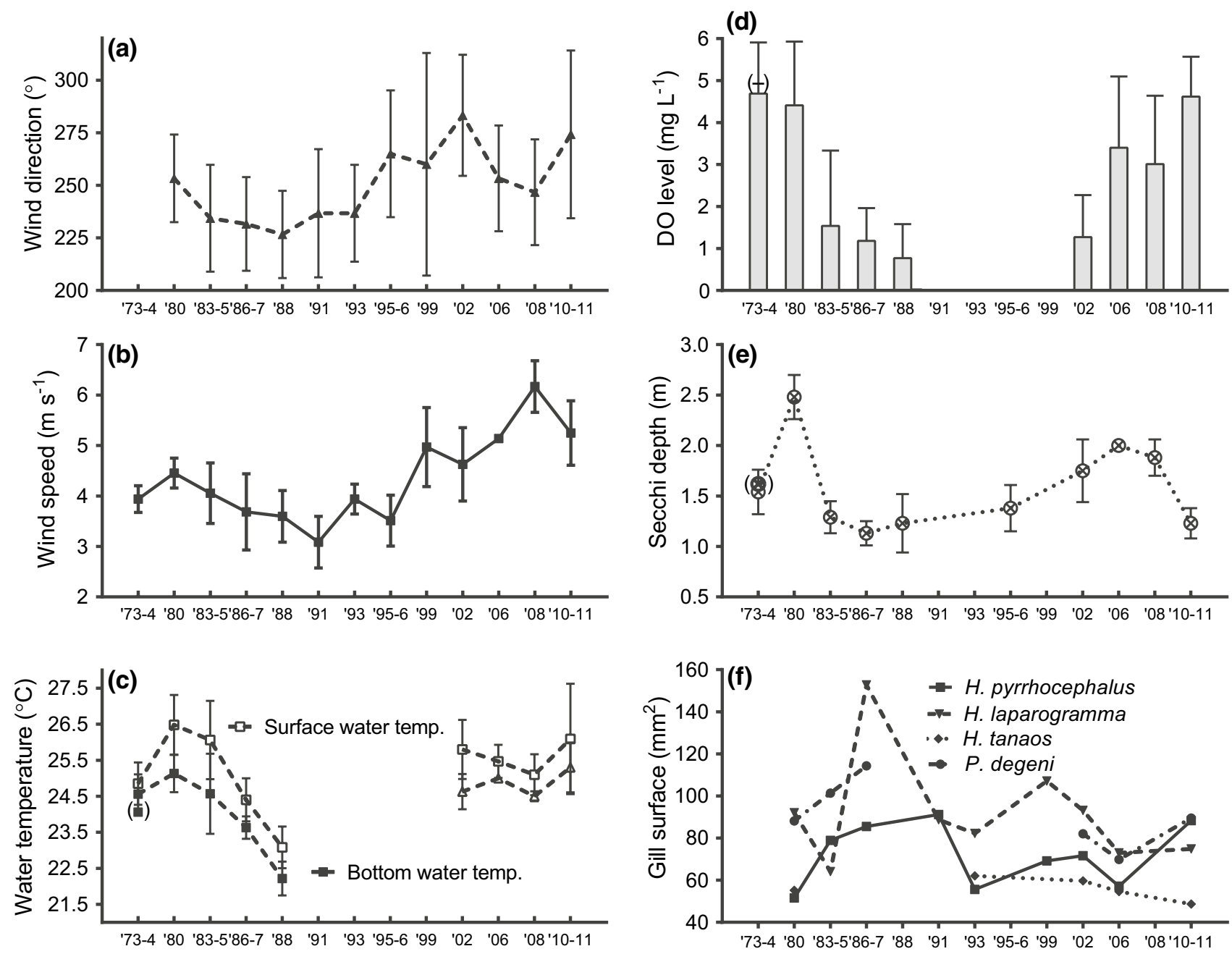

Period

Fig. 3 Environmental variables of the periodic dataset and approximated gill surface area of four haplochromine species plotted through time measured during the wet season (February-April). a Wind direction $(N=12)$, b wind speed $(N=13)$, $\mathbf{c}$ bottom and surface water temperature $(N=9)$, d DO-level $(N=9)$, e Secchi depth $(N=10)$, f estimated marginal means of the gill surface area of the second gill arch of four haplochromine species: pyr and lap $(N=9)$, tan $(N=5)$ and $\operatorname{deg}(N=6)$. Water temperature, DO-levels and Secchi depth were measured at station G. Corrected values from Akiyama et al. (1977) are indicated in parentheses. Dissolved oxygen levels and water temperature have not been measured in the period 19911999. From 1988 till 2001 there were no fish available for $d e g$ and from 1982 to 1992 no fish were available for tan. Only the upper end standard deviations are depicted for DO-levels. Depicted standard deviations are based on three monthly within year measurements for wind direction and speed, 3-12 periodic measurements within period (e.g., 1983-1985) for water temperature, DO-level and Secchi depth and number of individuals measured per year for gill surface area rainfall during those periods. PC1 shows a negative relationship with the gill surface area of all four species. However, these trends are not significant after sequential Bonferroni correction $(P<0.05$ for lap and $\operatorname{deg}, P<0.10$ for pyr and tan; Table 2; Fig. 5). There was, however, a significant overall effect of PC1 on the gill surface area of the four species $(P=0.004)$. The second $P C$ axis explains $18.5 \%$ and was positively related with the maximum air temperature and lake level, while minimum air temperature and wind speed show a negative relation. There was no significant overall effect of PC2 on the gill surface area of the four species.

\section{Discussion}

This study shows how climatic variability, and not only cultural eutrophication, can influence tropical lake dynamics on the relatively small scale of the Mwanza Gulf. Based on our results, we hypothesize that, together with eutrophication, wind speed drives vertical mixing and thereby modifies water quality of the lake, in particular, dissolved oxygen, which may drive changes in the gill surface area of the haplochromine cichlids in the Mwanza Gulf of Lake Victoria (and Lake Victoria at large, Lehman 1998). 
Table 1 Correlations of environmental variables from the annual dataset

\begin{tabular}{|c|c|c|c|c|c|c|}
\hline Environmental variable & Rainfall & Min. air temp. & Max. air temp. & Lake level & Wind direction & Wind speed \\
\hline Rainfall & $\mathrm{X}$ & & & & & \\
\hline Min. air temp. & $\begin{array}{l}r=0.005 \\
P=0.973\end{array}$ & $\mathrm{X}$ & & & & \\
\hline Max. air temp. & $\begin{array}{l}r=-0.347 \\
P=0.015\end{array}$ & $\begin{array}{l}r=0.253 \\
P=0.079\end{array}$ & $\mathrm{X}$ & & & \\
\hline Lake level & $\begin{array}{l}r=-0.02 \\
P=0.898\end{array}$ & $\begin{array}{l}r=-0.138 \\
P=0.366\end{array}$ & $\begin{array}{l}r=-0.386 \\
P=0.011\end{array}$ & $X$ & & \\
\hline Wind direction & $\begin{array}{l}r=-0.314 \\
P=0.062\end{array}$ & $\begin{array}{l}r=0.078 \\
P=0.651\end{array}$ & $\begin{array}{l}r=0.200 \\
P=0.272\end{array}$ & $\begin{array}{l}r=-0.060 \\
P=0.737\end{array}$ & $\mathrm{X}$ & \\
\hline Wind speed & $\begin{array}{l}r=-0.353 \\
P=0.023\end{array}$ & $\begin{array}{l}r=0.380 \\
P=0.014\end{array}$ & $\begin{array}{l}r=0.352 \\
P=0.032\end{array}$ & $\begin{array}{l}r=-0.322 \\
P=0.046\end{array}$ & $\begin{array}{l}r=0.396 \\
P=0.017\end{array}$ & $\mathrm{X}$ \\
\hline
\end{tabular}

Significant correlations after sequential Bonferroni correction (environmental variable as subgroup) are indicated in bold

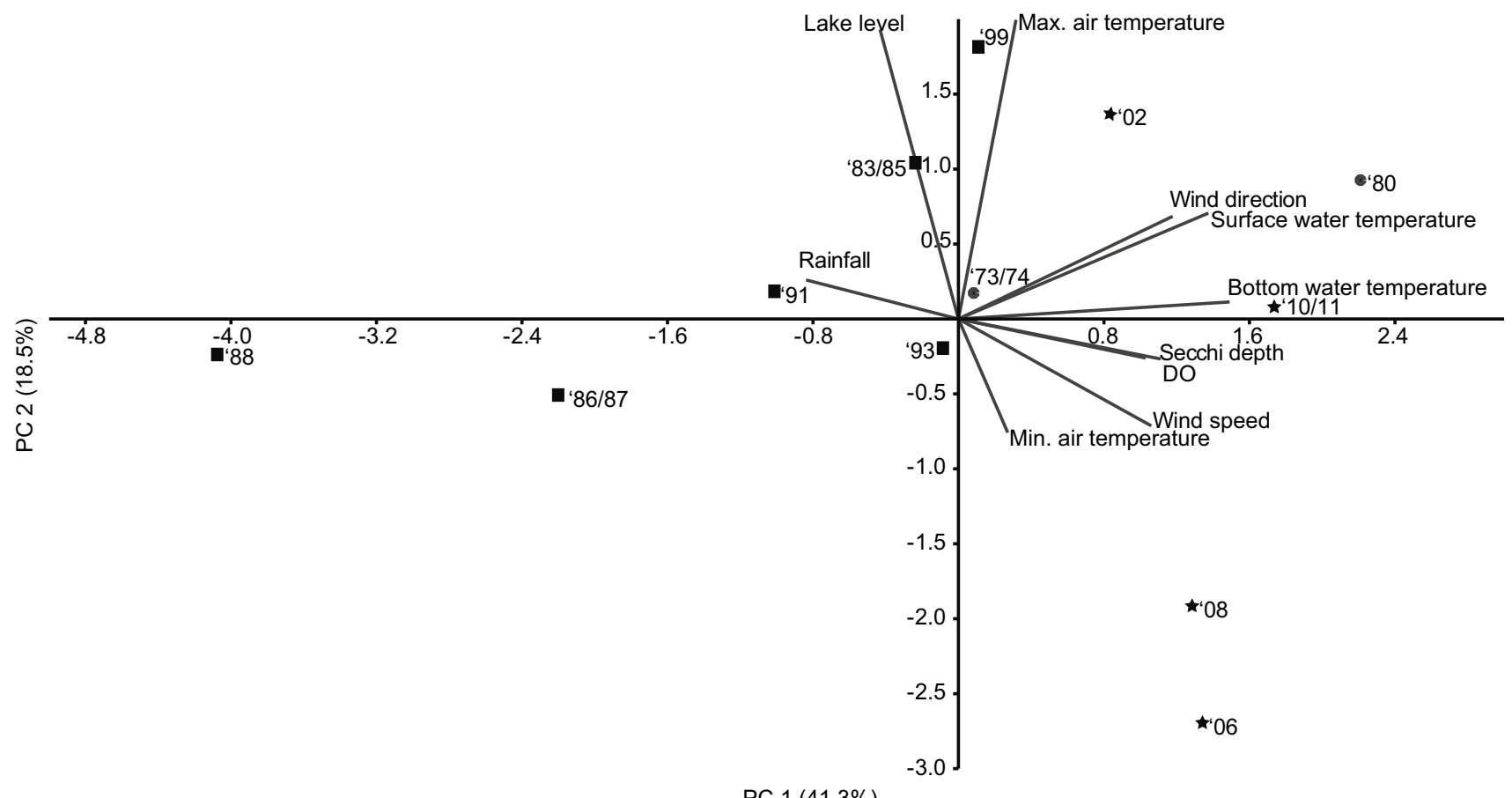

Fig. 4 PCA ordination of axis 1 (PC1) explaining $41.3 \%$ and axis 2 (PC2) explaining $18.5 \%$ of averaged meteorological data and environmental variables throughout time. Circles indicate years before, squares indicate years during, and stars indicate years after severe environmental changes. Sample sizes (number of time periods) per

\section{Environmental changes through time}

Wind speed tends to be higher when the wind is coming from the west and lower when the wind is coming from the south and southwest ( $r=0.396, P=0.017$, Table 1). During the 1980s, the wind changed to a more southwest direction in combination with lower wind speeds. These lower wind speeds are likely to have resulted in reduced mixing meteorological and environmental variable: minimum air temperature, rainfall and wind speed $(N=12)$, maximum air temperature, wind direction and lake level $(N=11)$, DO-level, Secchi depth, surface and bottom water temperature $(N=9)$

of the water (Fish 1957; Hecky et al. 2010; Lehman 1998; MacIntyre 2013; MacIntyre et al. 2014; Stager et al. 2009; Talling 1966). This reduced mixing would have resulted in thermal stratification which in turn led to lower DO-levels and water temperature. Wind speed also tends to be lower when there is a lot of precipitation $(r=-0.353, P=0.023$, Table 1). The change in wind speed and direction indeed coincided with an increase of rainfall. Both the lower wind 
Table 2 Pearson correlations of gill surface area per species with $\mathrm{PC} 1$ and $\mathrm{PC} 2$

\begin{tabular}{lllll}
\hline Gill surface & PC1 & $P$ & PC2 & $P$ \\
\hline H. pyrrhocephalus & -0.52 & 0.07 & 0.14 & 0.71 \\
H. laparogramma & -0.60 & 0.04 & 0.07 & 0.85 \\
H. tanaos & -0.77 & 0.06 & 0.20 & 0.75 \\
P. degeni & -0.79 & 0.03 & 0.35 & 0.49 \\
\hline
\end{tabular}

None of the correlations remained significant after sequential Bonferroni correction ( $\mathrm{PC}$ axes as subgroups)

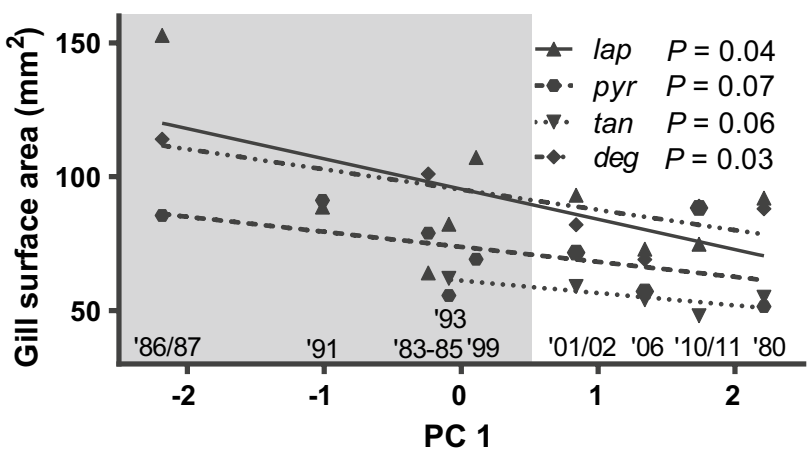

Fig. 5 Linear regression of PC1 and the estimated marginal means of the gill surface area of the second gill arch of the four species of haplochromine cichlids (lap, pyr, tan, deg) plotted with time periods indicated. Note that all data points from the period of severe environmental changes (indicated by the gray shading) are on the negative end of PC1. Sample sizes (number of time periods) of gill metrics per species: pyr and lap $(N=9)$, tan $(N=5)$ and $\operatorname{deg}(N=6)$

speed and higher rainfall are likely to have influenced the water transparency by reduced mixing and increased nutrient and sediment influx from the shores and watershed (Cornelissen et al. 2014) and nutrient input from the rainfall itself (Tamatamah et al. 2005). In addition, as suggested by Hecky et al. (2010), the lower wind speeds created optimal conditions for buoyant phytoplankton taxa (e.g., cyanobacteria) compared to rapidly sinking taxa such as diatoms (Reynolds 2006) that would reinforce the resulting decline in Secchi disc transparency. The increase of cyanobacteria has contributed to the decrease in water transparency and DO-levels in deeper waters as well (Hecky et al. 2010; Verschuren et al. 2002). Despite no overall change in rainfall over the period of record, the lake level decreased gradually over time reaching similar values as found in 1961-1962 (Yin and Nicholson 1998). This decrease is, based on our data, likely due to increased evaporation as a result of increased wind speed and maximum temperatures as wind speed tended to be positively correlated with both minimum $\left(r_{\mathrm{s}}=0.380, P=0.014\right)$ and maximum air temperature $(r=0.352, P=0.032)$ and is significantly negatively correlated with lake level as well. In addition, the maximum air temperature also tended to be negatively correlated with rainfall $(r=-0.347, P=0.015)$ that is partly caused by the increased cloud cover with increased rainfall reducing solar radiation, and with lake level $(r=-0.386$, $P=0.011$, Table 1). Next to the observed climatic changes, human management also regulates lake levels (Yin and Nicholson 1998). Especially, the sharp lake level decline during the 2000s can be for a large part attributed to the 1999 initial operation regime of the expanded hydropower facility in Uganda, the Kiira Dam (Swenson and Wahr 2009).

During the 2000s, the wind speed increased to levels higher than that recorded in the past 40 years. These high wind speeds are likely to have increased evaporation rates that probably have resulted in complete vertical mixing at our Mwanza Gulf study sites (MacIntyre 2013; MacIntyre et al. 2014; Talling 1966). Increased evaporation can cause vertical mixing as the daily warmed upper waters create a diurnal thermocline that is eroded by evaporationdriven nighttime cooling (MacIntyre 2013). This mixing seems to be responsible for the changes of environmental variables (higher DO-levels, generally higher Secchi depth except for 2011) to their former values from before severe eutrophication. Therefore, we predict that a future change in wind direction and a sequential drop in wind speeds will decrease vertical mixing resulting in increased stratification, and thereby decreasing DO-levels and water transparency, creating even harsher conditions for the haplochromine cichlids than experienced during the late 1980s (Kolding et al. 2008b).

Although we base our predictions on the Mwanza Gulf only, it might well be that the Mwanza Gulf is representative for many other gulfs and bays along the Lake Victoria shoreline that show similar signs of eutrophication (Gikuma-Njuru and Hecky 2005; Hecky et al. 2010; Mugidde 1993; Ngupula et al. 2012; Ochumba and Kibaara 1989). In fact, the enormous cichlid biodiversity is mainly determined from catches in and around the Mwanza Gulf as well as from several other gulfs and bays (Witte et al. 2007). These areas are not only important in terms of biodiversity, but over two million people depend directly on Lake Victoria's fisheries that are mainly exploited along the shoreline (LVFO-FMP-2 2008). In addition, decreased vertical mixing might not be limited to the inshore gulfs and bays, but would occur lakewide (Hecky et al. 2010).

\section{Adaptive responses of the cichlids}

Our results suggest that the environmental variables that loaded the most on PC1 (wind speed and direction, DO, Secchi depth, bottom and surface water temperature) are negatively correlated with cichlid gill surface area, while rainfall is positively correlated, although these correlations 
were not significant after sequential Bonferroni correction (Table 2). All environmental variables that loaded strongly on PC1 had similar loadings (with bottom water temperature having the highest), making it more complicated to disentangle a direct factor influencing gill surface area; nonetheless, DO would be the most obvious candidate influencing it, considering the direct effect of DO on gill surface area (Nilsson et al. 2012; Sollid and Nilsson 2006).

Unexpectedly, the DO-levels did not correlate with the gill surface area of the four studied species. The lack of significant correlations is probably due to shortcomings of the collected dataset. The environmental variables collected are presented as being static, while many of these variables (e.g., Secchi depth, DO-level) can vary within a day. These are instantaneous measurements while gill surface areas are responding to longer-term exposures to DO. So, the Secchi depth and DO-levels we measured on a few days may not adequately capture longer-term values for these parameters. Despite the lack of significant correlation between gill surface area and DO-levels, certain predicted trends can be recognized especially during the 1970s and 1980s.

When oxygen levels dropped in the 1980s, a significant increase of gill surface area was observed in three species (we lack sufficient data in the 1980s for the fourth species, tan). During the 2000s, when DO-levels have reached their former levels from before the severe eutrophication, gill surface area of these species decreases again. Although the gill surface area fluctuated during the 1990s and 2000s, it tended to be below the high surface areas reached when hypoxic conditions were most severe (late 1980s). However, in 2011, when water transparency decreased again, so did the gill surface area of the species pyr and deg. As the water transparency is largely controlled by the influx of sediment and increased cyanobacterial abundance, the decrease in transparency may make it more difficult for fish to extract oxygen from turbid water. In other words, the gill surface area might be sensitive to fouling by suspended material as has been found for fish gill cells by Campbell et al. (1997) and Galvez et al. (2008). So, as well as DO-levels in the ambient water per se, suspended material (which is partly reflected in Secchi depth, Silsbe et al. 2006; Cornelissen et al. 2014) might determine the need for a larger gill surface area.

Different habitats and ecomorphologies of the four species might well explain the slight interspecific differences in responses to the environmental changes. The species pyr and deg showed a similar increase in gill surface area during the 1980s, while that of lap fluctuated a bit more and reached an extremely large gill surface area in the late 1980s. Although pyr and lap are closely related sister species (Maeda et al. 2009; Witte and Witte-Maas 1987) with similar ecology (Goldschmidt et al. 1990), it has been suggested that the population of lap invaded the Mwanza
Gulf when numbers of zooplanktivorous haplochromines decreased after the upsurge of the Nile perch in the mid1980s (Goldschmidt et al. 1990; Witte et al. 1992; Witte and Witte-Maas 1987). The species lap used to occur at depths between 20 and $35 \mathrm{~m}$ in the southern part of the lake (Witte and Witte-Maas 1987) and was relatively rare on the transect; however, densities of lap increased dramatically in 1985 and declined shortly after that again in 1986 (Goldschmidt et al. 1990). The occurrence of lap in deep water will have exposed them to lower DO-levels than species naturally occurring on the transect with a maximum depth of only $14 \mathrm{~m}$ (van Oijen et al. 1981). So instead of an adaptive response to low DO-levels, lap could have been preadapted to low DO-levels by having a relatively large gill surface area already. The species tan did not show changes in gill surface area which might be explained by the species ecomorphology. As the cichlid head is densely packed with structures (Barel 1993) and tan is the slenderest haplochromine species of the lake, an increase of gill surface area might have been constrained by increased surrounding structures (e.g., increased volume of muscles determining crushing force as was found for pyr, Witte et al. 2008), despite the slight increase in head size of tan (van Rijssel and Witte 2013). The spatial constraints of the cichlid head, in combination with selection pressures on other morphological structures related to feeding and predation (Galis and Barel 1980; van Rijssel et al. 2015; van Rijssel and Witte 2013), are likely to explain why gill surface area only increased when oxygen levels were extremely low, and why gill surface area decreased when oxygen levels were relatively high in the other species. In addition, fishes may reduce gill surface area to lessen the uptake of heavy metals (Schjolden et al. 2007), reduce pathogen and parasite infection (Nilsson et al. 2012), or minimize costs associated with the fluxes of ions and water over the gill surface area (Wood and Randall 1973).

The increase of gill surface area as a response to hypoxic conditions is quite common in fish, including several cyprinids (crucian carp, goldfish) and cichlids (Chapman et al. 2000; Rutjes et al. 2009; Sollid et al. 2003, 2005). In these studies, the gill surface area increased as a result of phenotypic plasticity induced by hypoxic conditions in the laboratory. Differences between morphological responses under natural and laboratory conditions can shed more light on the mechanism behind these responses under natural conditions. Chapman et al. (2000) found that natural populations of the Lake Victoria cichlid Pseudocrenilabrus multicolor victoriae Seegers 1990 at low oxygen sites had longer filaments and larger secondary lamellae, while fish experimentally raised under hypoxia showed an increase in filament length and number only. They attributed this disparity in response to differences in selection pressure and morphological constraints. 
Plastic responses to hypoxia in the laboratory were also found for $H$. pyrrhocephalus (Rutjes 2006). Somewhat different from the findings of Chapman et al. (2000), the fish increased their gill surface area not only by spaceoccupying means (longer filaments), but also by means not related to space (larger secondary lamellae). The current study showed that all three species had longer gill filaments and two species ( $p y r$ and lap) larger secondary lamellae, while $d e g$ had an increased density of the secondary lamellae. Because the head volume and body size of these fish decreased or remained the same during the hypoxic period in the 1980s (J. C. van Rijssel, unpublished data; van Rijssel and Witte 2013), space-occupying changes were expected to be limited by morphological constraints. On the other hand, the reduction in eye size (Van der Meer et al. 2012; van Rijssel and Witte 2013; Witte et al. 2008), and the possible reduction of the muscle used for suction feeding (musculus sternohyoideus, Witte et al. 2008), might have acted as morphological trade-offs. Whether phenotypic plasticity or genetically based changes underlie the morphological changes remains unknown. As suggested by Chapman et al. (2000), it is likely that both mechanisms are involved in the observed adaptive responses.

All four studied cichlid species have recovered successfully, reaching abundances that are similar to those found in the 1970s (Kishe-Machumu et al. 2015). In contrast, the gill surface area of two other zooplanktivorous species that are thought to be extinct or extremely rare in the Mwanza Gulf, $H$. piceatus and $H$. (Y.) heusinkveldi, showed a decrease of gill surface area during the mid-1980s (J. C. van Rijssel, unpublished data). Although it is tempting to speculate that the lack of adaptive responses in gill surface area (and body shape, van Rijssel and Witte 2013) is partly responsible for local extinction of these species, without samples collected during the late 1980s, when oxygen levels dropped, we cannot infer causality from these seemingly maladaptive responses.

The observed decrease in body size as well as the decreased size at first maturity (commonly referred to as "stunting") of Lake Victoria cichlids during the 1980s have been attributed to selective trawling with large mesh sizes and size-selective predation of Nile perch (van Rijssel and Witte 2013; Witte et al. 1995). However, the increased hypoxia might have caused the reported stunting as well. In addition to an increased gill surface area, cichlids do show stunting as a response to hypoxia in plasticity experiments (Kolding et al. 2008a; Reardon and Chapman 2009). Moreover, stunting in tilapias has been suggested to be induced by low oxygen levels in small, shallow lakes (Kolding 1993; Vianny et al. 2015). Although it is likely that hypoxic conditions have contributed to the observed stunting, this phenomenon would be expected to reverse once DO-levels increased again, which is not the case. Lake Victoria's demersal haplochromines still mature at a small size during times of relatively high oxygen levels (van Rijssel and Witte 2013). Of the three suggested selection pressures causing stunting, only predation by Nile perch is currently present, albeit less prevalent than during the 1980s (Kayanda et al. 2009; van Rijssel and Witte 2013). In addition, no stunting has been reported for Lake Victoria haplochromines raised under hypoxic conditions (Rutjes 2006; Rutjes et al. 2007, 2009). In short, hypoxia might have contributed to the stunting, but does not seem to be a main cause.

\section{Threats of eutrophication to fish biodiversity}

The cichlids in Lake Victoria have withstood substantial climatic changes for at least 15,000 years (Johnson et al. 1996) and are apparently able to cope with such fluctuations. However, recent anthropogenic perturbations are likely to have exacerbated the effects of climatic changes that together resulted in eutrophication of the lake (Hecky 1993; Hecky et al. 2010; Verschuren et al. 2002). Lake Victoria is regarded to be in a new, relatively stable state with respect to productivity and the food web (Hecky et al. 2010; van Zwieten et al. 2016). Although some might consider that this is a recovery state, the recent signs of improvement are derived from environmental variables (e.g., increased oxygen levels and water transparency) that are only symptoms of eutrophication (Sitoki et al. 2010). In fact, eutrophication is still ongoing as phosphorous loadings continue to rise (Hecky et al. 2010). The reduction of phosphorous input is considered to be the only successfully proven method for reducing eutrophication (Schindler 2012) and would be a necessary solution for Lake Victoria. Yet, it must be noted that in highly eutrophic situations such as Lake Victoria, phytoplankton abundance as well as deep water oxygen conditions is under hydrodynamic control and no longer regulated by nutrients alone, as the current lake is nutrient saturated and light availability limits maximum algal biomass in deeper, offshore areas (Silsbe et al. 2006). The expression of algal abundance and blooms in the open lake will vary from year to year depending on the meteorological and dependent hydrodynamic variability. However, in the open lake, reduction of the likelihood of excessive algal biomass over many years will require reduction of nutrient inputs. On the other hand, in the Mwanza Gulf and in other shallow gulfs and embayments with shallow mixing depths, phytoplankton abundance can still partly be nutrient limited (Poste et al. 2013; GikumaNjuru et al. 2013; Cornelissen et al. 2014), indicating a direct beneficial effect of phosphorous input reduction on water quality.

The Lake Victoria cichlids have proven to adapt to a variety of environmental changes over the past 35 years (Katunzi et al. 2003; Kishe-Machumu et al. 2008, 2016; 
Van der Meer et al. 2012; van Rijssel et al. 2015, 2016; van Rijssel and Witte 2013; Witte et al. 2008). However, a state of decreased vertical mixing might be detrimental to cichlid biodiversity for two major reasons. First, decreased vertical mixing might result in a very hostile environment in which cichlids and other species cannot cope with the changed environment (Smith and Schindler 2009). The new environment might demand morphological, physiological or behavioral adaptations that cannot be achieved by the fish through high selection pressures or plasticity. Though cichlids have proven to be very plastic in the laboratory (Chapman et al. 2000; Gunter et al. 2013; Meyer 1987; Muschick et al. 2011; Rutjes 2006; Rutjes et al. 2009; Stauffer and Van Snik Gray 2004), there are boundaries to this plasticity that might be reached through the changed environment where species must deal with other selection pressures. Second, decreased vertical mixing is likely to co-occur with low water transparency and low oxygen levels which has been proven to reduce fish (including the Lake Victoria cichlids) biodiversity by hybridization (Seehausen et al. 1997; Taylor et al. 2006; Vonlanthen et al. 2012). In addition, reduced vertical mixing in combination with eutrophication can result in massive fish kills when sudden upwelling of anoxic water occurs, as observed in Lake Victoria during periods of stratification (Cornelissen et al. 2015; Ochumba 1990; Wanink et al. 2001).

The increased eutrophication and reduced vertical mixing pose a major threat to biodiversity and to the people depending on the fishes of the lake for their income or food supply. As the African population continues to expand, especially in areas surrounding the African Great Lakes (UNEP 2008), anthropogenic influences are likely to increase eutrophication by cumulative nutrient loading. In combination with climatic fluctuations such as reduced winds and increased rainfall that favor eutrophication, in time, the lake may undergo a second biodiversity crisis. For these reasons, we consider restrictions on anthropogenic nutrient inputs into the lake as the most important task for ecosystem management. In addition, it is imperative that environmental variables such as nutrient loadings, chlorophyll, Secchi depths and DO-levels will be monitored on a regular basis along with continued collection of meteorological data. By adequately monitoring these variables, we can improve our understanding of the effects of eutrophication on biodiversity and, with reductions in nutrient loading, moderate biodiversity losses in Lake Victoria and prevent biodiversity crises in other African lakes.

Acknowledgments We want to express our thanks to our colleagues from the Haplochromis Ecology Survey Team (HEST) and the Tanzania Fisheries Research Institute (TAFIRI) for support and co-operation during the fieldwork. We would like to thank Prof. Dr. Ole Seehausen, Dr. Ilse Cornelissen and the colleagues from Disentangling the Social and Ecological Drivers of Ecosystem Change in
Lake Victoria, Tanzania (SEDEC), for providing environmental data. We are grateful to Prof. Dr. Sally MacIntyre and Dr. Matthew Mcgee for critical comments on the manuscript. We are indebted to the Meteorological Agency in Tanzania and the Lake Victoria Basin Water Office for providing meteorological and lake level data. The research and fieldwork were financially supported by the Netherlands Organization for Scientific Research (NWO grant: ALW1PJ/07030), the Netherlands Foundation for the Advancement of Tropical Research (WOTRO Grants: W87-129, W87-161, W87-189, W84-282, W84488, WB84-587), by the Section of Research and Technology of the Netherlands' Ministry of Development Co-operation, the Netherlands Organization for International Cooperation in Higher Education (NUFFIC), the International Foundation for Sciences (IFS) and the Schure Beijerinck-Popping Fonds. The authors declare that they have no conflict of interest.

Author contribution statement FW, REH and JvR conceived and designed the study. SEM, JP, KvT, JDV, MKM, JHW and JvR obtained the morphological and/or environmental data. JvR analyzed the data and wrote the manuscript; all authors provided editorial advice.

\section{References}

Akiyama T, Kajumulo AA, Olsen S (1977) Seasonal variations of plankton and physicochemical condition in Mwanza Gulf, Lake Victoria. Bull Freshw Fish Res Lab 27:49-61

Barel CDN (1993) Concepts of an architectonic approach to transformation morphology. Acta Biotheor 41:345-381. doi:10.1007/ Bf00709371

Campbell PGC, Twiss MR, Wilkinson KJ (1997) Accumulation of natural organic matter on the surfaces of living cells: implications for the interaction of toxic solutes with aquatic biota. Can J Fish Aquat Sci 54:2543-2554. doi:10.1139/ cjfas-54-11-2543

Chapman LJ, Galis F, Shinn J (2000) Phenotypic plasticity and the possible role of genetic assimilation: hypoxia-induced tradeoffs in the morphological traits of an African cichlid. Ecol Lett 3:387-393. doi:10.1046/j.1461-0248.2000.00160.x

Clark CO, Webster PJ, Cole JE (2003) Interdecadal variability of the relationship between the Indian Ocean zonal mode and East African coastal rainfall anomalies. J Climate 16:548-554. doi:10.1175/1520-0442(2003)016<0548:Ivotrb>2.0.Co;2

Cornelissen IJM, Silsbe GM, Verreth JAJ, van Donk E, Nagelkerke LAJ (2014) Dynamics and limitations of phytoplankton biomass along a gradient in Mwanza Gulf, southern Lake Victoria (Tanzania). Freshw Biol 59:127-141. doi:10.1111/fwb.12253

Cornelissen IJM, van Zwieten PAM, Peter HK, Nagelkerke LAJ (2015) Nile perch distribution in south-east Lake Victoria is more strongly driven by abiotic factors, than by prey densities. Hydrobiologia 755:239-255. doi:10.1007/s10750-015-2237-x

Cozar A et al (2012) Basin-scale control on the phytoplankton biomass in Lake Victoria, Africa. PLoS One 7:e29962. doi:10.1371/journal.pone.0029962

Crampton WGR, Chapman LJ, Bell J (2007) Interspecific variation in gill size is correlated to ambient dissolved oxygen in the Amazonian electric fish Brachyhypopomus (Gymnotiformes: Hypopomidae). Environ Biol Fish 83:223-235. doi:10.1007/ s10641-007-9325-3

Dabruzzi TF, Bennett WA (2014) Hypoxia effects on gill surface area and blood oxygen-carrying capacity of the Atlantic stingray, Dasyatis sabina. Fish Physiol Biochem 40:1011-1020. doi:10.1007/s10695-013-9901-8 
Fish GR (1957) A seiche movement and its effect on the hydrology of Lake Victoria. Col. Of. Fish. Publ, London

Funk C et al (2008) Warming of the Indian Ocean threatens eastern and southern African food security but could be mitigated by agricultural development. Proc Natl Acad Sci USA 105:1108111086. doi:10.1073/pnas.0708196105

Galis F, Barel CDN (1980) Comparative functional morphology of the gills of African lacustrine Cichlidae (Pisces, Teleostei) —an eco-morphological approach. Neth J Zool 30:392-430

Galvez F, Donini A, Playle RC, Smith DS, O’Donnell MJ, Wood CM (2008) A matter of potential concern: natural organic matter alters the electrical properties of fish gills. Environ Sci Technol 42:9385-9390. doi:10.1021/Es8005332

Gikuma-Njuru P, Hecky RE (2005) Nutrient concentrations in Nyanza Gulf, Lake Victoria, Kenya: light limits algal demand and abundance. Hydrobiologia 534:131-140. doi:10.1007/ s10750-004-1418-9

Gikuma-Njuru P, Guildford SJ, Hecky RE, Kling HJ (2013) Strong spatial differentiation of $\mathrm{N}$ and $\mathrm{P}$ deficiency, primary productivity and community composition between Nyanza Gulf and Lake Victoria (Kenya, East Africa) and the implications for nutrient management. Freshw Biol 58:2237-2252. doi:10.1111/ fwb. 12205

Goldschmidt T, Witte F, De Visser J (1990) Ecological segregation in zooplanktivorous haplochromine species (Pisces, Cichlidae) from Lake Victoria. Oikos 58:343-355

Goudswaard K, Witte F, Chapman LJ (2002) Decline of the African lungfish (Protopterus aethiopicus) in Lake Victoria (East Africa). Afr J Ecol 40:42-52. doi:10.1046/j.0141-6707.2001.00335.x

Grant PR, Grant BR (2006) Evolution of character displacement in Darwin's finches. Science 313:224-226. doi:10.1126/science.1128374

Gunter HM, Fan SH, Xiong F, Franchini P, Fruciano C, Meyer A (2013) Shaping development through mechanical strain: the transcriptional basis of diet-induced phenotypic plasticity in a cichlid fish. Mol Ecol 22:4516-4531. doi:10.1111/Mec.12417

Hammer $\varnothing$, Harper DAT, Ryan PD (2001) PAST: paleontological software package for education and data analysis Palaeontol. Electron 4:1-9

Hecky RE (1993) The eutrophication of Lake Victoria. Verh Int Verein Limnol 25:39-48

Hecky RE, Mugidde R, Ramlal PS, Talbot MR, Kling GW (2010) Multiple stressors cause rapid ecosystem change in Lake Victoria. Freshw Biol 55:19-42. doi:10.1111/j.1365-2427.2009.02374.x

Hughes GM (1966) Dimensions of fish gills in relation to their function. J Exp Biol 45:177-195

Hughes GM, Morgan M (1973) Structure of fish gills in relation to their respiratory function. Biol Rev Camb Philos Soc 48:419-475

Johnson TC et al (1996) Late pleistocene desiccation of Lake Victoria and rapid evolution of cichlid fishes. Science 273:1091-1093. doi:10.1126/science.273.5278.1091

Katunzi EFB, Zoutendijk J, Goldschmidt T, Wanink JH, Witte F (2003) Lost zooplanktivorous cichlid from Lake Victoria reappears with a new trade. Ecol Freshw Fish 12:237-240. doi:10.1046/j.1600-0633.2003.00023.x

Kayanda R et al (2009) Status of the major commercial fish stocks and proposed species-specific management plans for Lake Victoria. Afr J Trop Hydrobiol Fish 12:15-21. doi:10.4314/ajthf. v12i1.57366

Kishe-Machumu MA, Witte F, Wanink JH (2008) Dietary shift in benthivorous cichlids after the ecological changes in Lake Victoria. Anim Biol 58:401-417. doi:10.1163/157075608x383700

Kishe-Machumu MA, van Rijssel JC, Wanink JH, Witte F (2015) Differential recovery and spatial distribution pattern of haplochromine cichlids in the Mwanza Gulf of Lake Victoria. J Gt Lakes Res 41:454-462. doi:10.1016/j.jglr.2015.03.005
Kishe-Machumu MA, van Rijssel JC, Poste A, Hecky RE, Witte F (2016) Stable isotope evidence from formalin-ethanol preserved specimens indicates dietary shifts and increasing diet overlap in Lake Victoria cichlids. Hydrobiologia. doi:10.1007/ s10750-016-2925-1

Kolding J (1993) Population dynamics and life-history styles of Nile tilapia, Oreochromis niloticus, in Ferguson's Gulf, Lake Turkana, Kenya. Environ Biol Fish 37:25-46

Kolding J, Haug L, Stefansson S (2008a) Effect of ambient oxygen on growth and reproduction in Nile tilapia (Oreochromis niloticus). Can J Fish Aquat Sci 65:1413-1424. doi:10.1139/F08-059

Kolding JP, Van Zwieten P, Mkumbo OC, Silsbe G, Hecky RE (2008b) Are the Lake Victoria fisheries threatened by exploitation or eutrophication? Towards an ecosystem based approach to management. In: Bianchi G, Skjodal HR (eds) The ecosystem approach to fisheries. Cab International, Rome, pp 309354. doi:10.1079/9781845934149.0309

Kramer DL (1987) Dissolved oxygen and fish behavior. Environ Biol Fish 18:81-92. doi:10.1007/bf00002597

Langerhans RB, Chapman LJ, Dewitt TJ (2007) Complex phenotypeenvironment associations revealed in an East African cyprinid. J Evol Biol 20:1171-1181. doi:10.1111/j.1420-9101.2006.01282.x

Lehman JT (1998) Role of climate in the modern condition of Lake Victoria. Theor Appl Clim 61:29-37. doi:10.1007/s007040050049

Lorke A, Tietze K, Halbwachs M, Wuest A (2004) Response of Lake Kivu stratification to lava inflow and climate warming. Limnol Oceanogr 49:778-783

LVFO-FMP-2 (2008) The Fisheries Management Plan 2 for Lake Victoria (2009-2014) prepared through the support of the Implementation of the Fisheries Management Plan (IFMP) EDF Project No. 8 ACP ROR 029, May 2008. LVFO, Jinja, Uganda

Maan ME et al (2004) Intraspecific sexual selection on a speciation trait, male coloration, in the Lake Victoria cichlid Pundamilia nyererei. Proc R Soc Lond B Biol Sci 271:2445-2452. doi:10.1098/rspb.2004.2911

MacIntyre S (2013) Climatic variability, mixing dynamics, and ecological consequences in African Great Lakes. In: Goldman CR, Kumagai M, Robarts RD (eds) Effects of global warming on freshwater ecosystems of the world: what can be done to reduce negative impacts?. Wiley, Chichester. doi:10.1002/9781118470596.ch18

MacIntyre S, Romero JR, Silsbe GM, Emery BM (2014) Stratification and horizontal exchange in Lake Victoria, East Africa. Limnol Oceanogr 59:1805-1838. doi:10.4319/lo.2014.59.6.1805

Maeda K et al (2009) Population structure of two closely related pelagic cichlids in Lake Victoria, Haplochromis pyrrhocephalus and $H$. laparogramma. Gene 441:67-73. doi:10.1016/j. gene.2008.11.008

McGee MD, Borstein SR, Neches RY, Buescher HH, Seehausen O, Wainwright PC (2015) A pharyngeal jaw evolutionary innovation facilitated extinction in Lake Victoria cichlids. Science 350:1077-1079. doi:10.1126/science.aab0800

Meyer A (1987) Phenotypic plasticity and heterochrony in Cichlasoma managuense (Pisces, Cichlidae) and their implications for speciation in cichlid fishes. Evolution 41:1357-1369

Milinski M, Bakker TCM (1990) Female sticklebacks use male coloration in mate choice and hence avoid parasitized males. Nature 344:330-333. doi:10.1038/344330a0

Mugidde R (1993) The increase in phytoplankton primary productivity and biomass in Lake Victoria (Uganda). Verh Int Verein Limnol 25:846-849

Muschick M, Barluenga M, Salzburger W, Meyer A (2011) Adaptive phenotypic plasticity in the Midas cichlid fish pharyngeal jaw and its relevance in adaptive radiation. BMC Evol Biol 11:116. doi:10.1186/1471-2148-11-116

Ngupula GW, Ezekiel CN, Kimirei IA, Mboni E, Kashindye BB (2012) Physical and chemical characteristics of the Tanzanian 
inshore and offshore waters of Lake Victoria in 2005-2008. Afr J Aquat Sci 37:339-345. doi:10.2989/16085914.2012.712503

Nicholson SE, Kim E (1997) The relationship of the El Nino Southern oscillation to African rainfall. Int $\mathrm{J}$ Climatol 17:117-135. doi:10.1002/ (Sici)1097-0088(199702)17:2<117:Aid-Joc84>3.0.Co;2-O

Nilsson GE, Dymowska A, Stecyk JA (2012) New insights into the plasticity of gill structure. Respir Physiol Neurobiol 184:214222. doi:10.1016/j.resp.2012.07.012

Ochumba PBO (1990) Massive fish kills within the Nyanza Gulf of Lake Victoria, Kenya. Hydrobiologia 208:93-99

Ochumba PBO, Kibaara DI (1989) Observations on blue-green algal blooms in the open waters of Lake Victoria, Kenya. Afr J Ecol 27:23-34

Ong KJ, Stevens ED, Wright PA (2007) Gill morphology of the mangrove killifish (Kryptolebias marmoratus) is plastic and changes in response to terrestrial air exposure. J Exp Biol 210:11091115. doi: $10.1242 / \mathrm{jeb} .002238$

O'Reilly CM, Alin SR, Plisnier PD, Cohen AS, McKee BA (2003) Climate change decreases aquatic ecosystem productivity of Lake Tanganyika, Africa. Nature 424:766-768. doi:10.1038/ Nature 01833

Parmesan C (2006) Ecological and evolutionary responses to recent climate change. Annu Rev Ecol Evol Syst 37:637-669. doi:10.1146/annurev.ecolsys.37.091305.110100

Pollock MS, Clarke LMJ, Dubé MG (2007) The effects of hypoxia on fishes: from ecological relevance to physiological effects. Environ Rev 15:1-14. doi:10.1139/a06-006

Poste AE, Hecky RE, Guildford SJ (2013) Phosphorus enrichment and carbon depletion contribute to high Microcystis biomass and microcystin concentrations in Ugandan lakes. Limnol Oceanogr 58:1075-1088

Reardon EE, Chapman LJ (2009) Hypoxia and life-history traits in a eurytopic African cichlid. J Fish Biol 75:1795-1815. doi:10.1111/j.1095-8649.2009.02429.x

Reynolds CS (2006) Ecology of phytoplankton. Cambridge University Press, Cambridge

Rutjes HA (2006) Phenotypic responses to lifelong hypoxia in cichlids. Ph.D. thesis, Leiden University, Leiden

Rutjes HA, Nieveen MC, Weber RE, Witte F, Van den Thillart GE (2007) Multiple strategies of Lake Victoria cichlids to cope with lifelong hypoxia include hemoglobin switching. Am J Physiol Regul Integr Comp Physiol 293:R1376-R1383. doi:10.1152/ ajpregu.00536.2006

Rutjes HA, de Zeeuw MP, van den Thillart GEEJM, Witte F (2009) Changes in ventral head width, a discriminating shape factor among African cichlids, can be induced by chronic hypoxia. Biol J Linn Soc 98:608-619. doi:10.1111/j.1095-8312.2009.01298.x

Saroglia M (2002) Morphometric adaptations of sea bass gills to different dissolved oxygen partial pressures. J Fish Biol 60:14231430. doi:10.1111/j.1095-8649.2002.tb02437.x

Schindler DW (2012) The dilemma of controlling cultural eutrophication of lakes. Proc R Soc B-Biol 279:4322-4333. doi:10.1098/ rspb.2012.1032

Schjolden J, Sorensen J, Nilsson GE, Poleo AB (2007) The toxicity of copper to crucian carp (Carassius carassius) in soft water. Sci Total Environ 384:239-251. doi:10.1016/j.scitotenv.2007.06.009

Seehausen O (2004) Hybridization and adaptive radiation. Trends Ecol Evol 19:198-207. doi:10.1016/j.tree.2004.01.003

Seehausen $O$ (2006) Conservation: losing biodiversity by reverse speciation. Curr Biol 16:R334-R337. doi:10.1016/j. cub.2006.03.080

Seehausen O, van Alphen JJM, Witte F (1997) Cichlid fish diversity threatened by eutrophication that curbs sexual selection. Science 277:1808-1811. doi:10.1126/science.277.5333.1808
Silsbe GM, Hecky RE, Guildford SJ, Mugidde R (2006) Variability of chlorophyll a and photosynthetic parameters in a nutrient-saturated tropical great lake. Limnol Oceanogr 51:2052-2063

Sitoki L, Gichuki J, Ezekiel C, Wanda F, Mkumbo OC, Marshall BE (2010) The environment of Lake Victoria (East Africa): current status and historical changes. Int Rev Hydrobiol 95:209-223. doi:10.1002/iroh.201011226

Smith VH, Schindler DW (2009) Eutrophication science: where do we go from here? Trends Ecol Evol 24:201-207. doi:10.1016/j. tree.2008.11.009

Sollid J, Nilsson GE (2006) Plasticity of respiratory structuresadaptive remodeling of fish gills induced by ambient oxygen and temperature. Respir Physiol Neurobiol 154:241-251. doi:10.1016/j.resp.2006.02.006

Sollid J, De Angelis P, Gundersen K, Nilsson GE (2003) Hypoxia induces adaptive and reversible gross morphological changes in crucian carp gills. J Exp Biol 206:3667-3673. doi:10.1242/ Jeb.00594

Sollid J, Weber RE, Nilsson GE (2005) Temperature alters the respiratory surface area of crucian carp Carassius carassius and goldfish Carassius auratus. J Exp Biol 208:1109-1116. doi:10.1242/Jeb.01505

Stager JC, Hecky RE, Grzesik D, Cumming BF, Kling H (2009) Diatom evidence for the timing and causes of eutrophication in Lake Victoria, East Africa. Hydrobiologia 636:463-478. doi:10.1007/s10750-009-9974-7

Stauffer JR, Van Snik Gray EV (2004) Phenotypic plasticity: its role in trophic radiation and explosive speciation in cichlids (Teleostei: Cichlidae). Anim Biol 54:137-158. doi:10.1163/1570756041445191

Swenson S, Wahr J (2009) Monitoring the water balance of Lake Victoria, East Africa, from space. J Hydrol 370:163-176. doi:10.1016/j.jhydrol.2009.03.008

Talling JF (1966) The annual cycle of stratification and phytoplankton growth in Lake Victoria (East Africa). Int Rev Gesamten Hydrobiol Hydrogr 51:545-621. doi:10.1002/ iroh. 19660510402

Tamatamah RL, Hecky RE, Duthie HC (2005) The importance of atmospheric deposition to the phosphorus loading of Lake Victoria. (East Africa). Biogeochemistry 73:325-344. doi:10.1007/ s10533-004-0196-9

Taylor EB, Boughman JW, Groenenboom M, Sniatynski M, Schluter D, Gow JL (2006) Speciation in reverse: morphological and genetic evidence of the collapse of a three-spined stickleback (Gasterosteus aculeatus) species pair. Mol Ecol 15:343-355. doi:10.1111/j.1365-294X.2005.02794.x

Tierney JE et al (2010) Late-twentieth-century warming in Lake Tanganyika unprecedented since AD 500. Nat Geosci 3:422-425. doi:10.1038/Ngeo865

UNEP (2008) Africa's Lakes: Atlas of our changing environment. Division of Early Warning and Assessment (DEWA). United Nations Environment Programme (UNEP). Earthprint.com, Nairobi, Kenya

Van der Meer HJ, van Rijssel JC, Wagenaar LC, Witte F (2012) Photopic adaptations to a changing environment in two Lake Victoria cichlids. Biol J Linn Soc 106:328-341. doi:10.1111/j.1095-8312.2012.01859.x

van Oijen MJP, Witte F, Witte-maas ELM (1981) An introduction to ecological and taxonomic investigations on the haplochromine cichlids from the Mwanza Gulf of Lake Victoria. Neth J Zool 31:149-174

van Rijssel JC, Witte F (2013) Adaptive responses in resurgent Lake Victoria cichlids over the past 30 years. Evol Ecol 27:253-267. doi:10.1007/s10682-012-9596-9 
van Rijssel JC et al (2015) Fast adaptive responses in the oral jaw of Lake Victoria cichlids. Evolution 69:179-189. doi:10.1111/ evo. 12561

van Rijssel JC, Hecky RE, Kishe-Machumu MA, Witte F (2016) Changing ecology of Lake Victoria cichlids and their environment: evidence from $\mathrm{C}^{13}$ and $\mathrm{N}^{15}$ analyses. Hydrobiologia. doi:10.1007/s10750-016-2790-y

van Zwieten PAM et al (2016) The Nile perch invasion in Lake Victoria: cause or consequence of the haplochromine decline? Can J Fish Aquat Sci 73:622-643. doi:10.1139/cjfas-2015-0130

Verburg P, Hecky RE, Kling H (2003) Ecological consequences of a century of warming in Lake Tanganyika. Science 301:505-507. doi:10.1126/science. 1084846

Verschuren D et al (2002) History and timing of human impact on Lake Victoria, East Africa. Proc R Soc Biol Sci Ser B 269:289294. doi:10.1098/rspb.2001.1850

Vianny N et al (2015) The responses of Nile tilapia Oreochromis niloticus (Linnaeus, 1758) in Lake Wamala (Uganda) to changing climatic conditions. Lakes Reserv Res Manag 20:101-119. doi:10.1111/lre.12091

Vollmer MK et al (2005) Deep-water warming trend in Lake Malawi, East Africa. Limnol Oceanogr 50:727-732

Vonlanthen P et al (2012) Eutrophication causes speciation reversal in whitefish adaptive radiations. Nature 482:357-362. doi:10.1038/nature10824

Wanink JH, Kashindye JJ, Goudswaard PCK, Witte F (2001) Dwelling at the oxycline: does increased stratification provide a predation refugium for the Lake Victoria sardine Rastrineobola argentea? Freshw Biol 46:75-85

Williams AP, Funk C (2011) A westward extension of the warm pool leads to a westward extension of the Walker circulation, drying eastern Africa. Clim Dyn 37:2417-2435. doi:10.1007/ s00382-010-0984-y
Winder M, Schindler DE (2004) Climate change uncouples trophic interactions in an aquatic system. Ecology 85:2100-2106. doi:10.1890/04-0151

Witte F, van Densen WLT (1995) Fish stocks and fisheries of Lake Victoria. A handbook for field observations. Samara Publishing, Cardigan, Dyfed

Witte F, Witte-Maas ELM (1987) Implications for taxonomy and functional morphology of intraspecific variation in haplochromine cichlids of Lake Victoria. In: From form to fishery. Ph.D. thesis, Leiden University, Leiden

Witte F et al (1992) The destruction of an endemic species flock-quantitative data on the decline of the haplochromine cichlids of Lake Victoria. Environ Biol Fish 34:1-28. doi:10.1007/BF00004782

Witte F, Goldschmidt T, Wanink JH (1995) Dynamics of the haplochromine cichlid fauna and other ecological changes in the Mwanza Gulf of Lake Victoria. In: Pitcher TJ, Hart PJB (eds) The impact of species changes in African lakes. Chapman \& Hall, London, pp 83-110

Witte F, Wanink JH, Kishe-Machumu M (2007) Species distinction and the biodiversity crisis in Lake Victoria. Trans Am Fish Soc 136:1146-1159. doi:10.1577/T05-179.1

Witte F et al (2008) Major morphological changes in a Lake Victoria cichlid fish within two decades. Biol J Linn Soc 94:41-52. doi:10.1111/j.1095-8312.2008.00971.x

Wood CM, Randall DJ (1973) Influence of swimming activity on water balance in rainbow trout (Salmo Gairdneri). J Comp Physiol 82:257-276

Woodward G, Perkins DM, Brown LE (2010) Climate change and freshwater ecosystems: impacts across multiple levels of organization. Philos Trans R Soc Lond B Biol Sci 365:2093-2106. doi:10.1098/rstb.2010.0055

Yin XG, Nicholson SE (1998) The water balance of Lake Victoria Hydrolog Sci J 43:789-811. doi:10.1080/02626669809492173 